\title{
Alcoholic Chronic Pancreatitis and Exocrine Pancreatic Insufficiency
}

\author{
Raffaele Pezzilli* \\ Department of Gastroenterology Digestive Diseases, Sant'Orsola-Malpighi Hospital, Italy
}

Submission: February 22, 2017; Published: February 28, 2017

"Corresponding author: Raffaele Pezzilli, Department of Gastroenterology Digestive Diseases, Sant'Orsola-Malpighi Hospital, Pancreatic Unit, Bologna, Italy, Fax: 390512144148; Email: raffaele.pezzilli@aosp.bo.it

\begin{abstract}
The alcoholic pancreatitis continues to stimulate controversy. One of the most debated issues is whether the onset is a chronic disease or if it progresses to a chronic form after repeated episodes of acute pancreatitis and histological studies of patients with alcoholic pancreatitis have shown that the disease is chronic ab initio and that the acute alcoholic pancreatitis occurs in pancreas already damaged by chronic injury.

Late manifestations are the exocrine and endocrine insufficiency and the consequence of exocrine pancreatic insufficiency is the maldigestion and malabsorption of lipids, named steatorrhea, which causes weight loss and malnutrition. The preparations of microspheres have an excellent therapeutic efficacy as demonstrated by the improvement of the lipid absorption coefficient, increase in body weight, reduction in stool frequency, stool compaction and reduction and abdominal pain due to the accelerated intestinal transit of fats undigested. The response to the treatment of pancreatic insufficiency is clinically evaluated carefully to the recovery of body weight, improvement in symptoms associated with steatorrhea and therefore the improvement of patients' quality of life. It should be kept in mind that alcoholic patients are unwilling to follow a therapy and especially to adhere to the dietary recommendations.
\end{abstract}

Keywords: Chronic pancreatitis; Alcohol; Pancreatic extracts

\section{Alcohol Consumption on Serum Pancreatic Levels}

In occasional drinkers, the levels of serum amylase are abnormally elevated in approximately $13 \%$ of patients, while pancreatic lipase and isoamylase can be abnormally elevated in serum in only $2 \%$ of the cases [1] and the reason may be due to the fact that alcohol can act on the salivary glands. In chronic alcoholics without abdominal pain, amylase and lipase in serum are elevated in $14 \%$ of subjects and in patients with acute alcoholic pancreatitis, pancreatic amylase and isoamylase are elevated in $94 \%$ of cases and is generally more sensitive lipase (100\% of cases) [1]. Elevated levels of serum pancreatic enzymes are not related to an alcohol-related pancreatic pathology since the pancreatic damage was caused by chronic alcohol abuse and not to an occasional alcoholic intoxication.

\section{Chronic Alcoholic Pancreatitis}

The alcoholic pancreatitis continues to stimulate controversy. One of the most debated issues is whether the onset is a chronic disease or if it progresses to a chronic form after repeated episodes of acute pancreatitis. Histological studies of patients with alcoholic pancreatitis have shown that the disease is chronic ab initio and that the acute alcoholic pancreatitis occurs in pancreas already damaged by chronic injury. Genetic factors may play a role in the pathogenesis of alcoholic disease. The incidence of alcoholic chronic pancreatitis appears to have decreased over the last twenty years thanks to a use [2].

In 1998, Lankisch \& Banks [3] have reported that the prevalence of chronic pancreatitis in many parts of the world seemed to be in the range of $3-10$ per 100,000 people [3]. The majority of cases of chronic pancreatitis require hospitalization for the presence of pain and the occurrence of other complications such as pseudocysts [2].

In Italy, according to data reported by the Ministry of Health in 2005 [4], the proportion of patients discharged to chronic pancreatitis is 32.9 per 100,000 hospitalized patients. The age of the majority of these patients varies from 45 to 64 years and most of them are males. The hospital stay is 9.8 days and this duration of hospitalization is higher than that of patients with digestive diseases different from chronic pancreatitis (7.5 days). There is no doubt that, in Western countries, alcohol is the most common factor associated with chronic pancreatitis; alcoholic chronic pancreatitis primarily affects young adults of 30-40 
years of age, and its prevalence is higher in males. In Western countries in the period 1940-2003, alcohol, as an etiological factor of chronic pancreatitis, increased in frequency from 19 to $50 \%$ [2]. The early manifestation of chronic pancreatitis is the episodic or persistent pain and late manifestations are the exocrine and endocrine insufficiency.

\section{Physiology and Pathophysiology of Pancreatic Secretion and its Consequences}

The pancreas secretes more than 2 liters per day of pancreatic juice and it is constituted for approximately $97 \%$ water and electrolytes (mainly produced by the ductal cells) and for about $3 \%$ of enzymes capable of digesting fats, proteins and carbohydrates and they are mainly produced by the acinar cells [5]. The pancreas produces enzymes normally more than what is needed for normal digestion of food and the secretion is not compromised as long as there is a loss of pancreatic exocrine function of about $90 \%$ [6]. The digestive capacity of the different enzymes is also affected by intraluminal factors and the enzymes undergo to proteolytic degradation, inactivation by gastric acid, and their short half-life. Lipase is particularly susceptible to all these factors, which explains the reason why the maldigestion of fatty is more severe than that of carbohydrates and proteins. It is also important to know that for an efficient digestion of triglycerides in addition to the lipase a $\mathrm{pH}>6$ is required in the duodenum-jejunum which is created to the hydro-electrolytic pancreatic secretion and the intervention of both colipase and bile salts that are able to degradate fatty acids and suitable for the attack of the lipase and, thus, available for absorption by the intestinal mucosa $[7,8]$.

The main consequence of exocrine pancreatic insufficiency is the maldigestion and malabsorption of lipids, named steatorrhea, which causes weight loss and malnutrition. In chronic pancreatitis fibrosis replaces the pancreatic acinar cells and consequently causes a decrease in secretion of lipase and colipase; failing the buffering action of the pancreatic secretion, the intestinal luminal $\mathrm{pH}$ is lowered resulting in further inactivation of lipase. It has thus not only a maldigestion of fat in the diet but also of fatsoluble vitamins (A, D, E, and K) and malabsorption of vitamin B12. The presence of steatorrhea also worsens the quality of life of patients with chronic pancreatitis [9]. Micronutrient deficiency, fat-soluble vitamins, and lipoproteins seem to be associated with increased morbidity for the increased risk of malnutrition-related complications determining abnormalities in lipid metabolism and cardiovascular events [10]. Patients with alcoholic pancreatitis have low levels of total cholesterol, high density lipoprotein (HDL), apolipoprotein A1 (apoA1), and lipoprotein (a) [Lp (a)] compared to normal subjects and significantly lower levels of cholesterol, apoA1, apoprotein B (apoB), and Lp (a) of alcoholics without clinical signs of pancreatic or liver disease. The decrease levels of Lp (a) has been associated with an increased risk of atherogenic cardiovascular disease in patients with chronic pancreatitis [10].
Maldigestion of fat is the most common manifestation of exocrine pancreatic insufficiency as protein maldigestion, called azotorrhea, and sugars, such amylorrhea, are rare and present only in very advanced stages of chronic pancreatitis. Also the intestinal ecology, altered in patients with chronic pancreatitis and due to bacteria overgrowth may be present in $25-50 \%$ of patients having exocrine pancreatic insufficiency, and contributes to the partial failure of replacement therapy with pancreatic extracts [11].

\section{The Treatment of Pancreatic Maldigestion}

Currently in Italy there is a single pancreatic extract commercially constituted by microspheres protected by a gastroresistant film and encapsulated in a gelatin shell. The casing serves to protect the oral mucosa by the action of enzymes contained in the microspheres and the film serves to unlock the gastroresistant granules of pancreatic enzymes only when the $\mathrm{pH}$ is greater than 5.5 [8] Microspheres provide the advantage to allow a better mixing with the chyme [8]. The preparations of microspheres have an excellent therapeutic efficacy as demonstrated by the improvement of the lipid absorption coefficient, increase in body weight, reduction in stool frequency, stool compaction and reduction and abdominal pain due to the accelerated intestinal transit of fats undigested [12].

The recommended dose of pancreatic extracts per meal is 20000 units during the breakfast, 40000 during lunch and dinner and $20000 \mathrm{U}$ during snacks. Pancreatic extracts should be ingested during or immediately after a meal for a proper mix with food and maximal activity of enzymes; a normal diet increases the effectiveness of the extracts and a low intake of lipid reduces it. The use of acid-suppressing drugs with entericcoated pancreatin microspheres was not necessary except in the case of peptic disease associated [13] .The gut decontamination, supplementation of bile acids, and probiotics may be useful both to reduce the inflammatory response in the intestine which allows optimal effectiveness of pancreatic enzyme replacements in controlling the clinical signs and symptoms of pancreatic insufficiency $[11,14]$.

\section{How to Evaluate the Response to Treatment with Pancreatic Extracts}

The response to the treatment of pancreatic insufficiency is clinically evaluated carefully to the recovery of body weight, improvement in symptoms associated with steatorrhea and therefore the improvement of patients' quality of life [8].

It should be kept in mind that alcoholic patients are unwilling to follow a therapy and especially to adhere to the dietary recommendations; thus, they require a close clinical follow-up.

\section{References}

1. Pezzilli R (2015) Alcohol abuse and pancreatic diseases: an overview. Recent Pat Inflamm Allergy Drug Discov 9(2): 102-106.

2. Pezzilli R, Morselli-Labate AM (2009) Alcoholic pancreatitis: 
pathogenesis, incidence and treatment with special reference to the associated pain. Int J Environ Res Public Health 6(11): 2763-82.

3. Lankisch PG, Banks PA (1988) Pancreatitis (st edn). Springer-Verlag; Berlin, Germany.

4. Ministero del Lavoro, della Salute e delle Politiche Sociali.

5. Gullo L, Pezzilli R, Priori P, Baldoni F, Paparo F, et al. (987) Pure pancreatic juice collection over 24 consecutive hours. Pancreas 2(5): 620-623.

6. DiMagno EP, Go VL, Summerskill WH (1973) Relations between pancreatic enzyme outputs and malabsorption in severe pancreatic insufficiency. N Engl J Med 288: 813-815.

7. DiMagno EP, Malagelada JR, Go VL, Moutel CG (1977) Fate of orally ingested enzymes in pancreatic insufficiency. Comparison of two dosage schedules. N Engl J Med 296(23): 1318-1322.

8. Pezzilli R, Andriulli A, Bassi C, Balzano G, Cantore M, et al. (2003) Exocrine pancreatic insufficiency in adults: a shared position statement of the Italian Association for the Study of the Pancreas. World J Gastroenterol 19(44): 7930-7946.

9. Pezzilli R, Morselli-Labate AM, Ceciliato R (2005) Quality of life in patients with chronic pancreatitis. Dig Liver Dis 37: 181-189.
10. Montalto G, Soresi M, Carroccio A, Scafidi E, Barbagallo CM, et al. (1994) Lipoproteins and chronic pancreatitis. Pancreas 9(1): 137-138.

11. Pezzilli $R$ (2009) Chronic pancreatitis: maldigestion, intestinal ecology and intestinal inflammation. World J Gastroenterol 15(14): 1673-1676.

12. Seiler CM, Izbicki J, Varga-Szabó L, Czakó L, Fiók J, et al. (2013) Randomised clinical trial: a 1-week, double-blind, placebo-controlled study of pancreatin $25000 \mathrm{Ph}$. Eur. minimicrospheres (Creon 25000 MMS) for pancreatic exocrine insufficiency after pancreatic surgery, with a 1-year open-label extension. Aliment Pharmacol Ther 37(7): 691-702.

13. Sander-Struckmeier S, Beckmann K, Janssen-van Solingen G, Pollack $P$ (2013) Retrospective analysis to investigate the effect of concomitant use of gastric acid-suppressing drugs on the efficacy and safety of pancrelipase/pancreatin (CREON囚) in patients with pancreatic exocrine insufficiency. Pancreas 42(6): 983-989.

14. Pezzilli R, Barassi A, Morselli-Labate AM, Fantini L, Tomassetti $P$, et al. (2007) Fecal calprotectin and elastase 1 determinations in patients with pancreatic diseases: a possible link between pancreatic insufficiency and intestinal inflammation. J Gastroenterol 42(9): 754760 .

\section{Your next submission with JuniperPublishers will reach you the below assets}

- Quality Editorial service

- Swift Peer Review

- Reprints availability

- E-prints Service

- Manuscript Podcast for convenient understanding

- Global attainment for your research

- Manuscript accessibility in different formats

( Pdf, E-pub, Full Text, audio)

- Unceasing customer service

Track the below URL for one-step submission https://juniperpublishers.com/online-submission.php 